\title{
A REVIEW ON DIESEL INJECTORS MODELING, SPRAY AND CAVITATION
}

\author{
K. VEERANJANEYULU ${ }^{1} \& \mathrm{~T}$. VENKATESWAR RAO ${ }^{2}$ \\ ${ }^{I}$ Department of Mechanical Engineering, Research Scholar, Koneru Lakshmaiah Education Foundation, \\ Vaddeswaram, Guntur District, Andhra Pradesh, India \\ 2Department of Mechanical Engineering, Professor in DBS Institute of Technology, \\ Kavali, SPSR Nellore District, Andhra Pradesh, India
}

\begin{abstract}
This abstract is a literature review makes use of computational fluid dynamics (CFD) codes to model the incylinder fluid flow on a common rail direct injection diesel engine, turbulence and spray characteristics using fuel injectors, simulation and experimental work. This study is based on the reports of about 43 scientists, who published their results between 1995 to 2017. Most of the scientists and researchers used CFD codes to analyze the models under simulation conditions and compared these simulated results with the existing experimental results for different fuel injectors so as to reduce major pollutions like $N O_{X}$, Soot and other emissions. Some scientists have conducted experiments for the simultaneous reduction of $\mathrm{NO}_{X}$ and Soot with different engines by using different turbulence modelsReynolds-Averaged Approach, Larger Eddy Simulations model, Standard $k-\varepsilon$ model, RNG K-E Model, Realizable K-E Modeland Reynolds Stress Model (RSM). Scientists reported that among all the above turbulence models Re normalized Group (RNG) K-E model is the best applicable turbulence model for engine simulation. The KIVA code is widely used for model developments in academia due to the availability of the source. However, this code resolves complex geometries. On the other hand, other commercial CFD codes such as FLUENT, AVL FIRE, AVL BOOST, GT POWER, GT BOOST, STAR CD, FIRE, VECTIS and DIESEL-RK are frequently used by the industry due to their superior mesh generation interfaces and because of their available user support. Some scientists have considered the combination of STAR- CD and KIVA code, some researchers combined KIVA $3 \mathrm{~V}$ and FLUENT for the engine simulation using split injection, but they concluded that, it would be preferable to implement the advanced submodels directly into one commercial code for engine simulations.
\end{abstract}

\section{KEYWORDS: CFD \& FLUENT}

Received: Apr 13, 2018; Accepted: May 04, 2018; Published: May 30, 2018; Paper Id.: IJMPERDJUN201875

\section{INTRODUCTION}

Engine pollutant emissions are directly determined by the in-cylinder mixing and consequent combustion processes. Ahigh temperature is a condition that promotes the formation of $\mathrm{NO}_{\mathrm{X}}$ and soot. Thus, many techniques are being explored to reduce the local temperature in-cylinderSwirl can enhance mixing processes and may lead to a more homogeneous mixture. EGR can reduce $\mathrm{NO}_{\mathrm{X}}$ emissions by diluting the fresh mixture, because reduced oxygen concentration helps minimize thermal NO formation. Fluid flow in an internal combustion engine is one of the most challenging fluid dynamics problems to model. It is because the flow is associated with large density variations. Further, the fluid motion inside a cylinder is turbulent, unsteady both spatially and temporally. The combustion characteristics were greatly influenced by the details of the fuel preparation and the distribution of fuel in the engine cylinder which was mainly controlled by the in-cylinder fluid dynamics. Further, fuel injection introduces 
additional complexities. Pollutant emissions were controlled by the details of the turbulent fuel - air mixing and combustion processes. So, a dedicated understanding of these processes is required to improve performance and reduce emission without compromising fuel economy.

\section{IN -CYLINDER SPRAY}

F. Ruiz et al. have designed operation variables, fuel properties and injection systems have been studied. Author had commented that with the high injection pressure the better fuel spray will be obtained and this depends on L/ D ratio. If the ratio is between 1 to 5 the better atomization occurs. It was observed that as swirl number increases better fuel mixing and the penetration is not effective and swirl atomizer is best suited for small tangential ports with relatively large orifice diameters. With swirl atomizers large cone angle will have poor performance, whereas for a cone angle $30^{\circ}-60^{\circ}$ it would give better results $[1]^{1}$. Wanhua $\mathrm{Su}$ et al. focused on wall wetting as this prime parameter which determines the performance of an engine and responsible for emitting pollutions like soot and $\mathrm{NO}_{\mathrm{X}}$. As the fuel particles are touching the wall of a cylinder the particles get evaporated without participating in the combustion process, moreover the emission levels also will increase. A bump in the impinging region on a wall can effectively strip off the wall jet after the second jet is formed. There are limitations for the bump design that is the minimum height, for which strip off of the fuel should occur and this value, minimum height to thickness of the initial mixing layer is 0.25 to 0.33 . Effective design of the bump will improve the spray inside the combustion chamber and also avoids wall wetting [2]. Jian-Rong Qin et al. ${ }^{2}$ worked on research nozzle geometry and spray atomization characteristics have been studied in depth. By using turbulent break up model two kinds of nozzles valve covered orifice and mini SAC have been studied. Fuel injection parameters were incorporated in KIVA -II model with TAB model. The author concluded that change in nozzle geometry influences the atomization process. Importantly discharge coefficient and initial amplitude parameter are so important as they could be varied by the aspect ratio of the nozzle, needle valve shape and discharge direction [3]. Chang Sik Lee et $\mathrm{al}^{3}$. studied about the microscopic spray structure of diesel injector, spray tip penetration, particle motion analysis system at various injection pressures by using the Doppler particle analyzer. The computational results were compared with the experimental results conducted by the author [4]. K. H. Lee et $\mathrm{al}^{4}$. in this research work PIV method was used to determine the fluid dynamics information of the spray as fuel formation within the cylinder greatly influences the combustion characteristics. By using the Mie scattering method the fuel distribution is visualized. Finally, he concludes that spray is widely distributed according to the elapsed time after injection [5]. Essam $\mathrm{M}$ et al. focused on Spray characteristics were observed for HSDI engines with high pressure injection based on high speed photography, and the effects of injection pressure, nozzle size and injection style on spray are investigated. The author concluded the following points (1) higher injection pressure produced smaller SMD values, longer spray tip penetration and had a small effect on the spray angle.(2) At $45 \%$ load the effect of nozzle size on the spray characteristics was larger than the effect of nozzle cone angle. In other words the influence the droplet size are injection pressure and nozzle size.(3) At 45\% load and 90MPa injection pressure and increasing the spray angle by $20 \%$ have increased the $\mathrm{NO}_{\mathrm{X}}$ concentration by $16 \%$, and by decreasing the nozzle diameter by $9 \%$ then $\mathrm{NO}_{\mathrm{X}}$ concentration have been increased by 53\% [6]. For diesel jet impingement jet distribution depends on the obstacles geometry but not necessarily on number of obstacles. Author had concluded that small obstacles permit very good homogenization within the space that is combustion chamber. A multi jet structure also permits higher air enterainment as compared with a free jet configuration. All these effects would promote fast spatial distribution of diesel jets and, under hot conditions, faster vaporization and better mixing with air [7]. Jin Xiao et al. in his research, experiments have been conducted on jet diffusion flame characteristics of fuel containing dissolved $\mathrm{CO}_{2}$ gas with nozzle diameter as $0.19 \mathrm{~mm}$ and 
the injection pressure was kept constant. Different percentages of CO2concentrations 3.13\%, 7.18\%, $12.33 \%$ and $17.82 \%$ have been taken and experiments have been conducted [8]. I Sudhakar Das et al. worked on outwardly opened swirl injection has been considered for observing the spray characteristics. With modified spray break up model simulations have been conducted using computational fluid dynamics. Author observed that near the tip of the injector shows conical streams emanating from an outward opening injector have tendency to entrap air into the flow stream for better mixing and finer spray [9]. S. Gopalakrishnan et al. worked on multi -dimensional simulations have been carried out for flashing internal injector flow. The model is mass fraction of vapor which tends to the equilibrium quality based on the homogeneous relaxation model. The relaxation time is dependent on local pressure, vapor pressure and void fraction. Simulations have been carried and validated with the experimental results. Geometrically induced phase change similar to cavitation, near the nozzle entrance was observed. Three dimensional simulation run in asymmetric injector tip at high injection pressure showed reduced sensitivity to temperature [10]. Wei Ning et al. has developed three dimensional homogeneous equilibrium model has been developed and implemented into an engine CFD code KIVA 3V. The model was applied to simulate cavitating flow within injector nozzle passages. The effects of nozzle passage geometry and injection conditions on the development of cavitation zones and the nozzle discharge coefficient were investigated. Specifically, the effects of nozzle L/D ratio, R/D ratio and $\mathrm{K}$ were simulated and its effects of injection pressure and timevarying injection pressure were also investigated. These effects are well captured by nozzle flow model. Overall, it is found that the nozzle passage geometry has the most critical impact on the flow development inside nozzle and on the resulting nozzle discharge coefficient. Compared to cylindrical nozzles under the same injection conditions, converging nozzles tend to reduce cavitation and thus have larger nozzle discharge coefficients, while diverging nozzles increase cavitation and have smaller nozzle discharge coefficients. It is also cavitation and has larger discharge coefficients compared to sharp inlet nozzles under the same injection conditions [11]. Michele Battistoniet al. in his research work compared two different fuels a standard diesel fuel and pure bio- diesel, the methyl ester of soybean oil have been compared with regard to injection pressure. [12]. Jonas Galle et al. had focused on failure of the injectors and fuel, when bio diesel was used in engines after working for 50 to 1500 hours failure of injectors were taken place and he tried to improve the operation of the engine at the same time what are the reasons of failure of injectors. The different reasons were plastic deformation and clogging of injector's passage, microcracks, erosion and cavitation. It was also observed that physical and chemical composition of the fuel also places a role in the failure of injectors [13]. Author has concluded that with increased accuracy in the modeling of injector the full details of injector are crucial when comparing with the experimental results [14]. Lucio Postrioti et al. in his research a non-conventional diesel injection system is analyzed by means numerical and experimental investigation. The hydraulic behavior of DDI system has been analyzed in terms of injected volumes and injection rate time histories varying the injection pressures from 300 bars to 600 bars with a back pressure of 20 bars. The resulting process has been analyzed for spray evaluation along with droplet sizing and velocity in a pressurized test vessel in quiescent and room temperature. In order to validate in terms of liquid spray morphology, tip penetration and droplet sizing computations have been carried out along with the experiment. Steady Simulation of the nozzle, has been developed in order to gain correct flow rates and turbulence data at each of the nozzle holes exits. Then the Lagrangian spray simulations have been carried out by means of a new atomization approachable to take into account the cavitation phenomena and the turbulence effects. A tuning campaign has been performed in order to validate the secondary KH-RT breakup model, and a grid sensitivity analysis has been carried out [15]. Xusheng Zhang et al. focused on fuel atomization and vaporization process plays an important role in the combustion performance and emissions. This paper focuses on near 
nozzle spray characteristics for different injectors with different umbrella angle have been investigated using x ray phase contrast imaging and quantitative image processing. It was observed that dumbbell profile width composed of three stages was identified. For nozzle 5 for the same operating conditions the discharge coefficient was less. [20]. Tao Qiu et al. Worked on three dimensional numerical models have been developed for investigating the back pressure on inner cavitation during choking process. The results obtained by the numerical model had been validated with the experimental results under different boundary pressures which include varying injection pressure and back pressure. In this investigation the author concluded that for a given injection pressure, cavitation occurs with the drop in the back pressure [21]. Bo Wanget al. Research work was on optical based experiment had been conducted to study the deposit effect on the air fuel mixture preparation process on GDI engine, simultaneously computations were carried out using computational fluid dynamics. The author had used six different injection timings were used for complete simulation cycles. The injection pressure was 150 bars. The results have showed that the injector deposit would lead to lower the fuel mass flow rate with different injection pressures; the deposit was penetrated at longer length [22]. Yangbo Deng et al., in this research work experiments have been conducted on the flame structure on low swirl injector (LSI) for observing the flame structure, temperature distribution and exhaust gases for different swirl number and for different fuel composition. The PIV technique was used. Results have shown that injector generates a blue liftoff in the form of "W" which consists of four clusters of flames with pulsating yellowish color. A region wherein the high temperature region with two peaks on the profile. It was also observed that pollution levels dependent on thermal load and composition gas [23]. In this research work Fuying Xue et al. Focused on transient flow characteristics within the nozzle have been studied using computational techniques and validated to the existing experimental results. Computational results have closely followed by the experimental results. The author has analyzed the transient characteristics of P type asymmetric multi-hole nozzle with sac are analyzed. After the successful completion of simulations author concluded that the cavitation intensity is directly proportional to size of the nozzle hole angle. [24]. Raul Payri et.al designed a new nozzle for characterizing sprays formation. For understanding test rig which is fitted with injection rate meter was used to determine the flow characteristics at the nozzle exit. A high pressure 150 bars and temperature $1000 \mathrm{~K}$ chamber was used to determine liquid length and vapor penetration. Three different pintle nozzles have been tested with specific outlet section. The results showed that pintle nozzle offer great potential in terms of fuel mass flux controlled by variable nozzle geometry [26]. Hassan Mohammadi et.al. considered three different injector nozzle holes, cylindrical nozzle hole, convergent conical nozzle hole and convergent conical nozzle with rifling are investigated on liquid fuel flow. When compared to cylindrical and convergent nozzle the cavitation phenomenon occur in cylindrical nozzle, at the same time the in convergent conical nozzle velocity of fluid flow is higher than cylindrical nozzle hole as the frictional losses are less. Spray plume in case of cylindrical is wider than convergent conical nozzle hole. It was also observed that as penetration length of the spray is longer the formation of unburned hydrocarbons may increase and shorter the penetration mixing will be poor [27]. In this paper dynamic structure of bio-diesel and conventional fuel sprays were compared by Seoksu Moon et al. for single and multi-hole injectors using X-ray velocimetry technique. Spray structure of three types of fuels, bio-diesel, diesel and Viscor16br, were used in this study. Results have shown that high viscosity and density of bio-diesel decreased the velocity of injection compared to conventional fuels, but for multi-hole the effect was little bit reduced. For single hole the bio diesel the velocity of the fluid flow was low. Finally an author concluded that viscosity did not play an important role in spray dynamic structure [28]. Hyung Jun Kim et al. Studied the effect of fuel spray angles have been studied. Here two cone angles $60^{\circ}$ and $156^{\circ}$ were considered for observing the spray behavior, combustion and emissions using visualization 
system. Results have shown that $60^{\circ}$ injector have shown high cycle peak pressure, high heat release rate and low ignition delay. As emissions are concerned narrow angle had shown low hydrocarbons, carbon monoxide and $\mathrm{NO}_{\mathrm{X}}$ [29]. Wenbin et al. observed research on spray characteristics and injection momentum for piezoelectric and solenoid injectors were compared. Macroscopic spray characteristics were carried out with kerosene and diesel with piezoelectric injector. Piezoelectric injector response is faster in needle opening than solenoid injector; the spray penetration for kerosene is shorter than diesel at low injection pressure was observed. In addition better mixing in case of kerosene and longer ignition delay was observed and $\mathrm{PM}$ and $\mathrm{NO}_{\mathrm{X}}$ were reduced. [30]. Shengqi Wuet.al. did experimental investigation on a four hole prototype SIDI injectors for sub cooled and superheated conditions. All spray characteristics have been observed. The atomization process under superheated conditions was in fuel evaporation and outside nozzle fuel boiling caused by flash boiling. It was observed for L/D ratio 1.5, wider fuel plume than with of 0.5 ratio. Interaction between fuel plumes formed a closed region in the spray which may lead for spray collapse [31].

\section{MODELING}

Song-Charng Kong et al. conducted their research to understand the effects of nozzle a phenomenological model was developed by the author and implemented in AVLFIRE and KIVA II code for simulation of fuel injection and spray process. It is rather a multidimensional modeling in which it takes into account nozzle passage inlet configuration, flow losses and cavitation, the injection pressure and combustion chamber conditions and provides initial conditions for multidimensional spray modeling. This model was coupled with WAVE BREAK UP model for simulate the experiments of non-vaporizing sprays under diesel fuel conditions. The author had observed a good agreement was obtained in liquid penetration, spray angle and drip size (Sauter Mean Diameter) [34]. V. Lazarev et al. have designed a nozzle for studying hydrodynamic parameters and characteristics for injection nozzle and with an injection pressure capacity of 3000 bar. The nozzle was designed in such a way that the conic part of the needle had two radii for smooth distribution of the fuel and it also stabilizes the stream flow. The author mainly focused on needle position stability and injection process. In his design flow rate has been increased from $0.43 \mathrm{~kg} / \mathrm{h}$ to $0.6 \mathrm{~kg} / \mathrm{h}$, fuel flow stream was stabilized and injection process has been improved [35]. In this research detailed chemical kinetics used by Hoojoong Kim et.al for modeling low emissions in a HSDI diesel engine using different injectors. Here two injectors with $50^{\circ}$ and $130^{\circ}$ were used and the engine was operated on premixed charged compression ignition conditions, but operated under high intake temperatures and high EGR levels. RIF's model was used with KIVA code for combustion modeling and emissions. In case of wide angle in between 120-130 - the spray plays an important role in the combustion regimes. For SOI $-20^{\circ}$ ATDC combustion exhibits PCCI characteristics and for SOI $-30^{\circ}$ ATDC the fuel particles are impinging on the piston surface where in the soot formation was more. The author concludes that SOI has very important for $\mathrm{NO}_{\mathrm{X}}$ - soot trade-off [36].

\section{CAVITATION}

H. Chaves et al. carried out research work author had considered transparent nozzles of the same size that of the metallic nozzles and the same refractive index. In a steady flow test by keeping an injection pressure of 1000 bars video pictures of flow were captured. By using laser two focus velocimeter picture flows was measured. It was observed that above threshold pressure the injection depends on nozzle geometry and chamber pressure, cavitation appears at the sharp inlet corner of the nozzle and if the injection pressure gets increased the cavitation reaches the nozzle exit which is known as supercavitation [37]. Osman Asi et al. focused on a nozzle which was failed after running 400 hours which was made with $18 \mathrm{CrNi8}$ and it was case hardened steel used in a truck. The nozzle Study focused on the failure of this nozzle. 
Assessment has been done on its integrity that included a visual examination, photo documentation, chemical analysis, microhardness measurement and metallurgical examination. Failure zone was examined with the help of scanning electron microscope equipped with EDX facility. The author concluded that because of cavitation the failure of the injector taken place [39]. P. Maniarasan et al. worked on spray flash desalination system at low pressures and temperatures using swirl injectors. In this system water was sprayed into the vaporizer through a swirl injector as fine droplets. The vaporizer was maintained at low pressure and flow rate is $1 \mathrm{lt} / \mathrm{s}$. The injector performance was determined at different feed water temperatures, vacuum and water injection pressures. Droplet size of 0.7-0.9 $\mathrm{mm}$ from the theory compared to the experimental values. The author concludes droplet size is optimum for 0.7-0.9 mm [40]. Akira Sou et al. In their research studied a new combination of LES and Eulerian - Lagrangian Bubble tracking method and Rayleigh Plesset equation is used to simulate an incipient cavitation in which only cavitation bubble appears. A precursor simulation of a fully developed turbulent flow in a channel, in which periodic boundary condition is adopted for the inlet and exit, is carried out to generate inlet boundary condition for a nozzle simulation. To validate the model transient cavitation motion and turbulent velocity in a rectangular nozzle are acquired by using high speed camera and LDV. Author concluded that using LES with a fine grid RP equation for all nuclei tracked in a lagrangian manner [41]. Zhixia et al. attention was focused on transient flow characteristics in a real size diesel nozzle. With different injection pressures author had analyzed the cavitation inside the diesel nozzle and found that higher injection pressure leads to earlier cavitation inception. It was also observed that bubble discharge at the initial stage and bubble suction at the orifice exit as well. Moreover two types of string cavitation were observed, which constantly boost up the spray angle. It was found that the string cavitation has strong relation with the location of the needle [43].

\section{CONCLUSIONS}

At higher injections, pressures better spray was observed by affecting the discharge coefficient to a small extent. By means of designing a wall bump. The rich mixture accumulation on the wall of the combustion chamber in a small size engine can be eliminated and the near wall mixing rate can be greatly enhanced. Spray behavior was investigated with different techniques thoroughly. Early combustion injection has greatly influenced the combustion characteristics. Higher injection pressure produced smaller SMD values, longer spray tip penetration and had a small effect on the spray angle. With different injection angles using computation techniques, simulations have been carried and the competent angle had been identified for complete combustion of all injected particles. The cavitation phenomenon and its occurrence have been discussed widely with the given cavitation patterns. It was also understood how nozzle injector gets failed with respect to cavitation. After conducting a number of experiments the optimal diameter of the nozzle has been identified.

\section{REFERENCES}

1. F. Ruiz and N. Chigier The Effects of Design and Operating Conditionsof Fuel Injectors on Flow and Atomization SAE 870100 (1987) p1-10

2. Wanhua Su, Rongwen Lin, Hui Xie, and Shao-xi Shi Enhancement of near Wall Mixing of an Impinging SAE 870100 (1997) p22-32

3. Jian-Rong Qin, Tomohisa Dan and Ming-Chia LaiCorrelating the Diesel Behaviorto Nozzle Design Spray SAE1999-013555 (1999)p 1-13

4. Chang Sik Lee, Sung Wook Parkb An experimental and numerical study on fuel atomization characteristics, Fuel 81 (2002) p $2417-2423$ 
5. K. H. Lee, C. H. Lee, C. S. Lee An experimental study on the spray behavior and fuel distribution of GDI injectors using the entropy analysis and PIV method Fuel 83 (2004)p 971-980.

6. Essam M. EL-Hannouny, Taewon W. Lee, Patrick V. Farrell and Rolf D. Reitz An Experimental and Numerical Study of Injector Behavior for HSDI Diesel Engines2003-01-0705

7. $M$ Weclas and $R$ Faltermeier2 Diesel jet impingement on small cylindrical Obstacles for mixture homogenization by late injection strategyInt. J. Engine Res. Vol. 8 2007p 399-413

8. Jin Xiao, Zhen Huang, Xinqi Qiao, Yuchun Hou The effect of $\mathrm{CO} 2$ dissolved in a diesel fuel on the jet flame characteristics Fuel 87 (2008) p395-404

9. Sudhakar Das Fluid Dynamic Study of Hollow Cone Sprays SAE Technical Paper Series 2008-01-0131p1-7

10. S. Gopalakrishnan and David P. SchmidtA Computational Study of Flashing Flow in Fuel Injector nozzles SAE Technical Series 2008-01-0141p1-11

11. Wei Ning and Rolf D. Reitz A Numerical Investigation of Nozzle Geometryand Injection Condition Effects on Diesel Fuel Injector Flow Physics SAE Technical Series 2008-01-0936p1-23

12. Michele Battistoni Carlo Nazareno Grimaldi Numerical analysis of injector flow and spray characteristics from diesel injectors using fossil and biodiesel fuels Applied Energy 97 (2012) p656-666

13. Jonas Galle, Sebastian Verhelst, Roger Sierens, Leonardo Goyosb, Rafae Castaneda, Failure of fuel injectors in a medium speed diesel engineoperating on bio-oil biomass and bio energy 40 ( 2012 )p 27-35

14. M. Arienti, M. Sussman An embedded level set method for sharp interfaceMultiphase simulations of Diesel injectors International Journal of Multiphase Flow 59 (2014) p1-14

15. Lucio Postrioti, Simone Malaguti Experimental and numerical characterization of a direct solenoid actuation injector for Diesel engine applications Fuel 118 (2014) p316-328

16. Xusheng Zhang, Seoksu Moon, Jian Gao, Eric M. Dufresne, Kam Fezzaa Wang Experimental study on the effect of nozzle hole-to-hole angle on the near-field spray of diesel injector using fast X-ray phase-contrast imaging

17. Radboud Pos, Roger Cracknell, Lionel Ganippa Transient of diesel characteristics sprays from a deposit rich injector Fuel 153 (2015) p183-191

18. Sharma, Nikunj. "Algae an Alternative Source of Biodiesel."

19. Hadi Taghavifar, Mohammad Taghi Shervani-Tabar, Majid Abbasalizadeh Numerical study of the effects of injector needle movement and nozzle inclination angle on the internal fluid flow and spray structure of a group-hole nozzle layout Applied Mathematical Modeling (2015)

20. Ehsanallah Tahmasebi, Numerical simulation of Diesel injector internal flow field Energy Procedia 82 (2015) p 51 - 58

21. L.-Y. Zhou, S.-F. Donga, H.-F. Cui, X.-W. Wu, F.-Y. Xue, F.-Q. Luo Measurements and analyses on the transient discharge coefficient of each nozzle hole of multi-hole diesel injector Sensors and Actuators A 244 (2016) p 198-205

22. Tao Qiu, Xin Song, Effect of back pressure on nozzle inner flow in fuel injector Fuel 173 (2016) 79-89

23. Bo Wang, Tawfik Badawy Investigation of deposit effect on multi-hole injector spray characteristics and air/fuel mixing process Fuel 191 (2017) p10-24 
24. Yangbo Deng Combustion and exhaust emission characteristics of low swirl injector Applied Thermal Engineering 110 (2017) $171-180$

25. Fuying Xue Fuqiang Luo Numerical analyses of transient flow characteristics within each nozzle hole of an asymmetric diesel injector. International Journal of Heat and Mass Transfer 104 (2017) p 18-27

26. V. S. Yaliwal Effect of nozzle and combustion chamber geometry on thePerformance of a diesel engine operated on dual fuel mode using renewable fuels Renewable Energy 93 (2016) p483to 501

27. Raul Payri Study of new prototype pintle injectors for diesel engineapplication Energy Conversion and Management 122 (2016) p419-427

28. Hassan Mohammadi Numerical investigation on the hydrodynamics of the internal flow and spray behavior of diesel fuel in a conical nozzle orifice with the spiral rifling like guides Fuel 196 (2017) p $419-430$

29. Seoksu Moon Novel insights into the dynamic structure of biodiesel andconventional fuel sprays from high-pressure diesel injectors Energy 115 (2016) p 615-625

30. Hyung Jun Kim Impact of fuel spray angles and injection timing on the combustion and emission characteristics of a highspeed diesel engine Energy 107 (2016)p 572-579

31. Senthilkumar, P., and G. Sankaranarayanan. "Production of Waste Polyethylene Bags in to Oil and Studies Performance, Emission and Combustion Characteristics in DI Diesel Engine."

32. Wenbin Macroscopic spray characteristics of kerosene and diesel based on two different piezoelectric and solenoid injectors, Experimental Thermal and Fluid Science 76 (2016) p12-23

33. Shengqi Wu Near-nozzle spray and spray collapse characteristics of spark-ignition direct-injection fuel injectors under subcooled and superheated conditions Fuel 183 (2016) p 322-334

34. Chunde Yao Impacts of nozzle geometry on spray combustion of high pressure common rail injectors in a constant volume combustion chamber Fuel 179 (2016) p 235-245

35. Tianyun A comprehensive study on the factors affecting near-nozzle spray dynamics of multi-hole GDI injectors article in press

36. Song-Charng Kong and Rolf D. Reitz. Modeling the Effects of Injector Nozzle Geometry on Diesel Sprays SAE 1999-01-0912 p $1-14$

37. V. Lazarev Modeling of Injection Parameters for Diesel Engine InjectorNozzles with the Additional Precision Guiding Interface Procedia Engineering 150 ( 2016 ) p52 - 60

38. Hoojoong Kim and Rolf D. Reitz Modeling Combustion and Emissions ofHSDI Diesel Engines Using Injectors with Different Included Spray Angles SAE 2006-01-1150 P1-11

39. H. Chaves Experimental Study of Cavitation in the Nozzle Hole of Diesel Injectors Using Transparent Nozzles SAE $950290 p$ $197-211$

40. C. A rcoumanis Visualisation of cavitation in diesel engine injectorsMec. Ind. (2001) 2, p375-381

41. Osman Asi Failure of a diesel engine injector nozzle by cavitation damage Engineering Failure Analysis 13 (2006) p11261133

42. P. Maniarasan Design and performance evaluation of swirl injectors for water evaporation at low pressure Desalination 235 (2009) p 139-145 
43. Akira Sou Numerical simulation of incipient cavitation flow in a nozzleof fuel injector Computers \& Fluids 103 (2014) p 4248

44. F. J. Salvador Using a homogeneous equilibrium model for the study of the inner nozzle flow and cavitation pattern in convergent-divergent nozzles of diesel injectors Journal of Computational and Applied Mathematics accepted paper

45. Zhixia Visual experiment of transient cavitating flow characteristics in the real-size diesel injector nozzle International Communications in Heat and Mass Transfer 78 (2016) p13-20 
